\title{
High EGFR protein expression and exon 9 PIK3CA mutations are independent prognostic factors in triple negative breast cancers
}

William Jacot ${ }^{1,2}$, Caroline Mollevi ${ }^{3}$, Frédéric Fina ${ }^{4}$, Evelyne Lopez-Crapez ${ }^{2}$, Pierre-Marie Martin ${ }^{4}$, Pierre-Emmanuel Colombo ${ }^{5}$, Frédéric Bibeau ${ }^{6}$, Gilles Romieu ${ }^{1}$ and Pierre-Jean Lamy ${ }^{7,8^{*}}$

\begin{abstract}
Background: Triple negative breast cancers (TNBC) are a more aggressive subset of breast cancer. A better understanding of its biology could allow the rational development of targeted therapies.

Methods: We extensively analyzed the EGFR/PI3K/PTEN axis in a large, homogeneous population of TNBC to help defining the putative role of anti-EGFR and -PI3K targeted therapies in this setting. EGFR gene amplification, EGFR protein expression, PIK3CA and PTEN gene alterations (two members of EGFR downstream pathways) and their clinicopathological and prognostic implications were analyzed in 204 TNBC samples from European patients.

Results: EGFR amplification was detected in 18 of the 204 TNBC specimens (8.9\%) and was significantly associated with higher EGFR protein levels. Fourteen PIK3CA mutations were identified in exon 9 (6.7\%), and 17 in exon 20 (8.3\%). PIK3CA mutations, especially in exon 9, were significantly associated with grade I-II tumors. PTEN deletions were detected in 43 samples (21.50 \%) and were significantly associated with grade III tumors $(p<0.001)$. Univariate analysis showed a significant association between relapse-free survival (RFS), T and N stage and exon 9 PIK3CA mutations. Overall survival was significantly associated with T stage, N stage and adjuvant chemotherapy, which was administered to $70.3 \%$ of patients. In multivariate analyses, T stage, N stage, presence of exon 9 PIK3CA mutations and high EGFR protein level were independent poor prognostic factors for RFS, while adjuvant chemotherapy was associated with a better outcome.

Conclusions: High EGFR protein expression and exon 9 PIK3CA activating mutations are independent prognostic factors in TNBC. The efficacy of anti-PI3K targeted therapies needs to be evaluated in this setting.
\end{abstract}

Keywords: Triple negative, Breast cancer, EGFR, Gene amplification, PI3K, PTEN

\section{Background}

Triple negative breast cancers (TNBC) occur most frequently in young women and tend to have a more aggressive behavior. They are characterized by a relapse rate that rapidly rises in the first 2 years after diagnosis, peaks at 2-3 years post-diagnosis and declines during the next 5 years [1]. Currently, chemotherapy is the only systemic therapeutic option for this tumor type because

\footnotetext{
*Correspondence: pierre-jean.lamy@icm.unicancer.fr

${ }^{7}$ Department of Oncogenetics, Montpellier Cancer Institute Val d'Aurelle, 208, rue des Apothicaires, Montpellier F-34298, France

${ }^{8}$ Biological Ressources Center, Montpellier Cancer Institute Val d'Aurelle, 208, rue des Apothicaires, F-34298 Montpellier, France

Full list of author information is available at the end of the article
}

hormonal therapies and anti-HER2agents are ineffective due to the lack of expression of these therapeutic targets in tumor cells.

The transmembrane tyrosine kinase epidermal growth factor receptor (EGFR), which is encoded by the EGFR gene located on the short arm of chromosome 7, is frequently (30-52 \%) overexpressed in TNBC [2], particularly in the basal-like subgroup, and is associated with poor prognosis [3]. EGFR activation through its tyrosine kinase domain leads to recruitment of downstream effectors and activation of proliferative and cell survival signaling pathways [4]. In historical reports, EGFR overexpression, using various detection methods, 
was observed in 14 to $91 \%$ of breast tumors [5]. In more recent works, EGFR protein expression was detected in 16 to $36 \%$ of breast cancers [6]. In addition, EGFR expression is part of the diagnostic criteria used to identify basal-like TNBC, a TNBC subgroup with worse prognosis [2]. However, the mechanisms responsible for EGFR expression in TNBC remain poorly understood. We previously reported [7], consistently with most of the published data [8,9], the absence of EGFR activating mutations in TNBC samples from Caucasian patients. Therefore, the putative effect of EGFR TKIs in this population cannot be linked to activating mutations but, possibly, to EGFR overexpression or gene amplification [8-11]. Indeed, other EGFR modifications have been described in TNBC. Increased EGFR gene copy number has been inconstantly $(0-51 \%)$ reported in some EGFR-positive breast cancers [4, 8-12]. Cell membrane EGFR expression was associated with increased gene copy number in two of these studies $[4,12]$, but not with chromosome 7 polysomy in the report by Burness et al. [4]. Due to the high disparities in results and methods used for EGFR status evaluation, a comprehensive analysis of this putative target in TNBC is required.

The PI3K/PTEN pathway is involved both in EGFR downstream signaling and in TNBC physiopathology [13]. Mutations in PIK3CA (the gene encoding the p110 catalytic subunit of PI3K) and PTEN loss of expression (LOE) have been detected in breast cancers [14]. PTEN LOE has been observed in 50-82 \% of basal-like breast cancers [15]. PTEN LOE appears to be the main cause of PI3K pathway alterations in breast cancer and is strongly associated with hormone receptor positivity [16], although it is observed also in $8-25 \%$ of TNBC [11, 17, 18]. Conversely, PIK3CA mutations were detected in only a small fraction of TNBC with basal-like features in Martin's study [11]. The high frequency of PTEN LOE and the low occurrence of PIK3CA mutations in TNBC with basal-like features might bring support to the still debated hypothesis of the mutual exclusivity of these two alterations $[14,15]$.

Herein, we report the results of the analysis of EGFR gene amplification, EGFR expression and PIK3CA and $P T E N$ deletion and their clinicopathological and prognostic implications in a large, comprehensive set of 204 European patients with TNBC.

\section{Methods}

\section{Patients and tumor samples}

A total of 1695 consecutive patients with breast cancer referred to the Val d'Aurelle Montpellier Cancer Institute (ICM) between 2002 and 2010 were prospectively entered in the database of a dedicated tumor DNA bank (Biobank number BB-0033-00059). Samples were isolated from frozen, histologically proven and macro-dissected invasive breast cancer specimens that were primarily handled for ER and PR testing by using the dextran charcoal method, as previously described $[19,20]$, or for uPA/PAI-1 quantification with the Femtelle ${ }^{\oplus}$ test. Tumors were considered as ER and PR positive when the receptor concentration was higher than $10 \mathrm{fmol} / \mathrm{mg}$ of protein (using the Dextran Charcoal Assay [DCC]), or $>10 \%$ tumor cells were stained by immunohistochemistry (IHC) [21]. HER2 status was determined based on HER2 protein expression level by IHC using the A485 monoclonal antibody (Dako, Denmark). Tumors with HER2 scores of 0 and 1+ were considered as HER2 negative. In tumors with equivocal HER2 IHC test results (2+), gene amplification was evaluated using fluorescence or chromogenic (CISH) in situ hybridization. Specimens with HER2 3+ scores were considered as HER2 positive. Finally, 204 DNA samples from non-metastatic TNBC were selected for this study. Each individual treatment proposal was in accordance with our institution guidelines [22]. The clinicopathological characteristics and treatments of the 204 patients included in this study are summarized in Table 1. This study was reviewed and approved by the Montpellier Cancer Institute Institutional Review Board (ID number ICM-URC-2014/73). All patients gave their written, informed consent. As part of the study evaluated the prognostic impact of biological markers, this manuscript adheres to the REMARK guidelines.

\section{Tissue processing and DNA extraction}

DNA was extracted during tumor sample protein extraction protocol for either ER/PR or uPA PAI quantification. Briefly, each frozen tumor specimen was pulverized in liquid nitrogen and homogenized in a Polytron homogenizer (Glen Mills, NJ, USA) with a cytosol extraction buffer (20 mM Tris. HCI, $1.5 \mathrm{mM}$ ethylenediaminetetraacetic acid [EDTA], $10 \mathrm{mM} \mathrm{Na2MoO4,} 1.5 \mathrm{mM}$ dithiothreitol and $10 \%$ glycerol, $\mathrm{pH} \mathrm{7.4;} \mathrm{in} \mathrm{the} \mathrm{case} \mathrm{of} \mathrm{tumors}$ processed for ER and PR testing using the DCC assay) or with Triton X-100 buffer (in the case of tumors processed for uPA/PAI-1 testing using the Femtelle kit, American Dignostica) with a buffer:tissue ratio of 10:1 (volume/weight) and centrifuged at 10,000 $\times \mathrm{g}$ for $15 \mathrm{~min}$. Total genomic DNA was extracted from the pellets obtained by centrifugation of either cytosol or Triton extract using the QIAamp DNA extraction minikit (ref 51304, Qiagen, Hilden, Germany) according to the manufacturer's protocol. Supernatants were used to prepare cytosol or Triton X-100 protein extracts and the total protein content was quantified using the Pierce assay (BCA Protein Assay Kit, Pierce Biotechnology, Rockford, IL) as previously described [23]. 
Table 1 Patients and tumors' characteristics

\begin{tabular}{|c|c|c|}
\hline & Number of patients & (\%) \\
\hline & 204 & 100 \\
\hline \multicolumn{3}{|l|}{ Age } \\
\hline Median, range & 56 & $29-86$ \\
\hline$<55$ years & 98 & 48.0 \\
\hline$\geq 55$ years & 106 & 52.0 \\
\hline \multicolumn{3}{|l|}{ T } \\
\hline $\mathrm{T} 1$ & 84 & 41.2 \\
\hline $\mathrm{T} 2$ & 97 & 47.5 \\
\hline T3 & 10 & 4.9 \\
\hline T4 & 13 & 6.4 \\
\hline \multicolumn{3}{|l|}{ N } \\
\hline NO & 132 & 64.7 \\
\hline N1 & 46 & 22.5 \\
\hline N2 & 18 & 8.8 \\
\hline N3 & 8 & 3.9 \\
\hline \multicolumn{3}{|l|}{ Histology } \\
\hline Ductal & 163 & 79.9 \\
\hline Lobular & 13 & 6.4 \\
\hline Other $^{a}$ & 28 & 13.7 \\
\hline \multicolumn{3}{|l|}{ SBR-EE grade } \\
\hline 1 & 9 & 4.5 \\
\hline 2 & 60 & 29.9 \\
\hline 3 & 132 & 65.7 \\
\hline $\mathrm{NE}$ & 3 & \\
\hline \multicolumn{3}{|c|}{ Adjuvant chemotherapy } \\
\hline No & 60 & 29.7 \\
\hline Yes & 142 & 70.3 \\
\hline Missing & 2 & \\
\hline
\end{tabular}

${ }^{a} 6$ invasive papillary carcinomas, 4 metaplastic carcinomas, 4 undifferentiated carcinomas, 3 apocrine carcinomas, 3 medullary carcinomas, 3 mixed ductal-lobular carcinomas, and one/each of the following histological subtypes: sarcomatoid carcinoma, adenoid cystic carcinoma, adenosquamous and neuroendocrine carcinoma $N E$ not evaluated

\section{PIK3CA mutation detection}

Polymerase Chain Reaction (PCR) amplification and High Resolution Melting [24] analysis were performed on a Rotor-Gene $6000^{\mathrm{rm}}$ instrument (Corbett Research, Mortlake, New South Wales, Australia) using the Light Cycler 480 HRM Master MIX kit (Ref 04909631 001, Roche Diagnostics, Meylan, France). Primers were designed to amplify PIK3CA fragments that span the exon 9 hotspot mutation region including the p.E542X and p.E545X mutations, and the exon 20 region including the hotspot mutations p.H1047X, p.H1048X and p.G1049X (Additional file 1: Table S1). Genomic DNA samples from MCF7 cells (c.1633G > A, p.E545K mutation) and T47D cells (c.3140 A $>$ G, P.H1047R) were used as positive controls for PIK3CA exon 9 and exon 20 heterozygous mutations, respectively. Water (no template) was used to control for PCR contamination.

After HRM analysis, PCR products were purified using the ExoSAP-IT kit (ref US78200, GE Healthcare Life Sciences, Saclay, France) according to the manufacturer's instructions. Purified PCR products were then used as templates for sequencing with the Big Dye Terminator v1.1 kit (Ref 4336774, Applied Biosystems Inc., Foster City, CA). After migration completion, the PIK3CA sequences were analyzed with the Applied Biosystems Sequencing Analysis ${ }^{\oplus}$ software v5.2.

\section{EGFR amplification}

Quantitative PCR (qPCR) used in this study was previously described [25]. Briefly, EGFR copy number was normalized to beta-actin $(A C T B, 7 \mathrm{p} 22.1)$, a gene located in the same chromosome, and to glyceraldehyde-3-phosphate dehydrogenase (GAPDH, 2p13.31), a gene located on another chromosome. We previously used this strategy [19] to distinguish between real copy number variations and aneusomy. One DNA sample with amplified EGFR was used as positive control $(E G F R / A C T B$ ratio $=12.67 \pm$ 2.31) and human placental DNA was used as normal control $(E G F R / A C T B$ ratio $=0.55 \pm 0.06)$. The theoretical threshold of gene amplification for a given sample was an $E G F R / A C T B$ ratio $=2$. Below this threshold, the sample was considered 'wild type' and above this threshold, the sample was considered 'amplified'.

Detection of PTEN and other chromosome 10 sequence copy number variations (CNV) by Multiplex Ligation-dependent Probe Amplification

Multiplex Ligation-Dependent Probe Amplification (SALSA MLPA probemix P225-D1 PTEN, MRC-Holland, Amsterdam, the Netherlands) is a high throughput, PCRbased method to determine the relative copy number of various human DNA target sequences. The method is based on the annealing of a mixture of oligonucleotides (Additional file 2: Table S2) to their cognate DNA sequences. DNA denaturation, hybridization, ligation, PCR and fragment analysis were performed according to the manufacturer's specification. Raw data were visually controlled and then normalized using the Coffalyser.Net software. For each electropherogram, height peaks and areas under the peaks were exported to Coffalyser.NET. The algorithm is based on a double normalization (intraand inter-sample) and calculates a quotient for each assay tube. The relative height of each individual probe peak, compared to the relative probe peak height of various reference DNA samples, reflects the relative copy number of the corresponding target sequence in the sample. Depending on the quotient value, DNA sequences were considered as normal, with heterozygous duplication, with 
heterozygous deletion, with homozygous deletion, or with non-interpretable results. This approach allows the identification of PTEN and chromosome 10q loss of heterozygosity $(\mathrm{LOH})$ and aneuploidy.

\section{EGFR protein level}

EGFR concentration in cytosol or Triton X-100 protein extracts was determined using the EGFR ELISA kit (MERCK ref CBA018), a sandwich enzyme immunoassay that employs specific goat anti-EGFR polyclonal antibodies. The range of standardization goes from $31.25 \mathrm{pg} / \mathrm{ml}$ to $2000 \mathrm{pg} / \mathrm{ml}$. EGFR levels were standardized to the total protein content and results expressed in $\mathrm{pg} / \mathrm{mg}$ of protein content. Because ranges of EGFR values were different according to sample preparation, EGFR expression was divided in terciles, for low, medium and high protein level.

\section{Statistical analysis}

Categorical variables were presented as frequency distributions and continuous variables as medians and ranges. Categorical variables were compared with the Pearson's chi-square or Fisher's exact test. Differences were considered statistically significant at the $p<0.05$ level. Overall survival (OS) was calculated from the date of surgery to the date of death (whatever the cause). Patients lost to follow-up were censored at the last documented visit. Relapse-free survival (RFS) was calculated from the surgery date to the recurrence date. Patients alive at the last follow-up without recurrence and patients lost to follow-up were censored at the time of the last followup. Patients who died without recurrence were censored at the date of death. The Kaplan-Meier method was used to estimate the OS and RFS rates. Differences in survival rates were compared using the log-rank test. Statistical analyses were performed with STATA 13.0 (StatCorp, College Station, TX).

\section{Results}

\section{Patients and Tumor's characteristics}

For this study, 204 DNA samples from TNBC specimens that included a high percentage $(>50 \%)$ of tumor cells, as required for ER and PR or UPA/PAI-1 testing, were selected. The main clinicopathological characteristics of this cohort are summarized in Table 1 and were consistent with the classical TNBC features (i.e., a majority of $\mathrm{T} 2+$ tumors, one third of $\mathrm{N}+$ cancers and high frequency of high grade tumors, as only nine tumor specimens [4.5\%, 3 ductal carcinomas, 3 ductal carcinomas with tubular inflexion, 1 lobular carcinoma, 1 invasive papillary carcinoma and 1 ductal carcinoma with cribriform inflexion] were classified as SBR-EE [Elston-Ellis modification of Scarff-Bloom-Richardson] grade 1). The patients' median age was 56 years (range: 29-86 years). Ductal carcinoma was the most common histological type (79.9\%), $70.3 \%$ of patients received adjuvant chemotherapy, while the remaining $29.7 \%$ of patients received adjuvant radiation therapy if clinically indicated. None of the patients received additional hormonal therapy, targeted therapy or an investigational product.

\section{EGFR/PI3K/PTEN pathway alterations and clinicopathological correlations}

The results of the assessment of the EGFR/PI3K/PTEN axis alterations and of the correlations between EGFR amplification, EGFR protein level, PIK3CA mutation, PTEN status and clinicopathological characteristics are summarized in Table 2. As previously reported [7], no EGFR-activating mutation was identified in our population. EGFR amplification was detected in 18 tumor samples $(8.9 \%)$ and was significantly associated with higher EGFR protein levels compared to TNBC specimens with normal or deleted EGFR or chromosome 7 polysomy $(p=0.043$, Fig. 1). PIK3CA mutations were identified in exon $9(n=14,6.7 \%)$ and in exon $20 \quad(n=17$, $8.3 \%$ ) (Additional file 3: Table S3). The presence of PIK3CA mutations was significantly associated with SBREE grade I-II tumors $(p=0.038)$, particularly in the case of exon 9 mutations $(64.3 \%$ vs. $35.7 \%, p=0.02)$. PTEN deletions were detected in 43 TNBC specimens (21.5\%) and were significantly associated with SBR-EE grade III tumors $(p<0.001)$. No other statistically significant association was identified between EGFR/PI3K/PTEN pathway alterations and clinicopathological parameters.

\section{Survival analyses}

Using May 1, 2014 as cut-off date, the median follow-up was 6.4 years (range: $0.1-12.8$ years). Forty seven deaths (5-year OS: $81.3 \%$ [74.8-86.3]) and 52 relapses occurred (5-year RFS: $76.1 \%$ [69.2-81.6]). The relapse pattern of our population was consistent with the previously reported relapse risk temporal distribution [1, 26], as most relapses occurred during the first 3 years of follow-up (Additional file 4: Figure S1 and Additional file 5: Figure S2). Univariate analysis (Table 3) showed a significant association between RFS and $\mathrm{T}$ stage, $\mathrm{N}$ stage and exon 9 PIK3CA mutations and a marginal association $(p=0.07)$ with adjuvant chemotherapy. OS was significantly associated with $\mathrm{T}$ stage, $\mathrm{N}$ stage, adjuvant chemotherapy and marginally with exon 9 PIK3CA mutations $(p=0.063)$ and EGFR status (Polysomy/Amplification vs. Deletion/Normal, $p=0.075)$. As some patients died from non-TNBC related causes, a multivariate analysis was performed using RFS data to identify independent, TNBC-specific prognostic factors. $\mathrm{T}$ stage, $\mathrm{N}$ stage, presence of exon 9 PIK3CA mutations and high EGFR protein level were identified as independent poor prognostic factors, while the use of adjuvant chemotherapy was statistically associated with a better outcome 
Table 2 Correlations between EGFR amplification, EGFR protein level, PIK3CA mutation, PTEN status and clinicopathological characteristics

\begin{tabular}{|c|c|c|c|c|c|c|c|c|c|c|c|c|c|c|c|c|c|c|c|c|c|c|c|c|c|c|c|c|}
\hline \multirow[t]{3}{*}{ Patients' characteristics } & \multicolumn{9}{|c|}{ EGFR gene status } & \multicolumn{7}{|c|}{ EGFR protein level } & \multicolumn{7}{|c|}{ PIK3CA mutations } & \multicolumn{5}{|c|}{ PTEN status } \\
\hline & \multicolumn{2}{|c|}{ Normal } & \multicolumn{2}{|c|}{ Deletion } & \multicolumn{2}{|c|}{ Amplifi-cation } & \multicolumn{2}{|c|}{ Polysomy } & \multirow[t]{2}{*}{$p$} & \multicolumn{2}{|c|}{ Lower tercile } & \multicolumn{2}{|c|}{ Middle tercile } & \multicolumn{2}{|c|}{ Upper tercile } & \multirow[t]{2}{*}{$p$} & \multicolumn{2}{|c|}{ Exon 9} & \multicolumn{2}{|c|}{ Exon 20} & \multicolumn{2}{|l|}{ No } & \multirow[t]{2}{*}{$p$} & Dele & etion & No o & eletion & $p$ \\
\hline & $\mathrm{N}$ & $\%$ & $\mathrm{~N}$ & $\%$ & $\mathrm{~N}$ & $\%$ & $\mathrm{~N}$ & $\%$ & & $\mathrm{~N}$ & $\%$ & $\mathrm{~N}$ & $\%$ & $\mathrm{~N}$ & $\%$ & & $\mathrm{~N}$ & $\%$ & $\mathrm{~N}$ & $\%$ & N & $\%$ & & $\mathrm{~N}$ & $\%$ & $\mathrm{~N}$ & $\%$ & \\
\hline Age & & & & & & & & 0.119 & & & & & & & 0.412 & & & & & & & 0.347 & & & & & 0.394 & \\
\hline$<55$ years & 76 & 49.3 & 6 & 54.5 & 11 & 61.1 & 5 & 25.0 & & 31 & 48.4 & 27 & 43.5 & 35 & 55.6 & & 5 & 35.7 & 6 & 35.3 & 87 & 50.3 & & 23 & 53.5 & 72 & 45.9 & \\
\hline$\geq 55$ years & 78 & 50.7 & 5 & 45.5 & 7 & 38.9 & 15 & 75.0 & & 33 & 51.6 & 35 & 56.5 & 28 & 44.4 & & 9 & 64.3 & 11 & 64.7 & 86 & 49.7 & & 20 & 46.5 & 85 & 54.1 & \\
\hline T status & & & & & & & & 0.878 & & & & & & & 0.836 & & & & & & & 0.384 & & & & & 0.387 & \\
\hline $\mathrm{T} 1$ & 63 & 40.9 & 4 & 36.4 & 9 & 50.0 & 8 & 40.0 & & 25 & 39.1 & 25 & 40.3 & 28 & 44.4 & & 8 & 57.1 & 8 & 47.1 & 68 & 39.3 & & 15 & 34.9 & 67 & 42.7 & \\
\hline T2+ & 91 & 59.1 & 7 & 63.6 & 9 & 50.0 & 12 & 60.0 & & 39 & 60.9 & 37 & 59.7 & 35 & 55.6 & & 6 & 42.9 & 9 & 52.9 & 105 & 60.7 & & 28 & 65.1 & 90 & 57.3 & \\
\hline N status & & & & & & & & 0.234 & & & & & & & 0.182 & & & & & & & 0.491 & & & & & 0.475 & \\
\hline NO & 103 & 66.9 & 6 & 54.5 & 8 & 44.4 & 14 & 70.0 & & 47 & 73.4 & 36 & 58.1 & 40 & 63.5 & & 11 & 78.6 & 10 & 58.8 & 111 & 64.2 & & 30 & 69.8 & 99 & 63.0 & \\
\hline $\mathrm{N}+$ & 51 & 33.1 & 5 & 45.5 & 10 & 55.6 & 6 & 30.0 & & 17 & 26.6 & 26 & 41.9 & 23 & 36.5 & & 3 & 21.4 & 7 & 41.2 & 62 & 35.8 & & 13 & 30.2 & 58 & 37.0 & \\
\hline SBR-EE grade & & & & & & & & 0.466 & & & & & & & 0.871 & & & & & & & 0.038 & & & & & $<0.001$ & \\
\hline$|-| \mid$ & 49 & 32.5 & 4 & 36.4 & 6 & 33.3 & 10 & 50.0 & & 22 & 34.9 & 19 & 30.7 & 21 & 34.4 & & 9 & 64.3 & 7 & 41.2 & 53 & 31.2 & & 4 & 9.8 & 63 & 40.4 & \\
\hline III & 102 & 67.5 & 7 & 63.6 & 12 & 66.7 & 10 & 50.0 & & 41 & 65.1 & 43 & 69.3 & 40 & 65.6 & & 5 & 35.7 & 10 & 58.8 & 117 & 68.8 & & 37 & 90.2 & 93 & 59.6 & \\
\hline Histology & & & & & & & & 0.102 & & & & & & & 0.974 & & & & & & & 0.103 & & & & & 0.526 & \\
\hline Ductal & 119 & 77.3 & 11 & 100 & 17 & 94.4 & 15 & 75.0 & & 50 & 78.1 & 50 & 80.7 & 50 & 79.4 & & 12 & 85.7 & 10 & 58.8 & 141 & 81.5 & & 36 & 83.7 & 123 & 78.3 & \\
\hline Lobular and other & 35 & 22.7 & 0 & 0.0 & 1 & 5.6 & 5 & 5.0 & & 14 & 21.2 & 12 & 19.3 & 13 & 20.6 & & 2 & 14.3 & 7 & 41.8 & 32 & 18.5 & & 7 & 16.3 & 34 & 21.7 & \\
\hline EGFR Gene Status & & & & & & & & & - & & & & & & 0.164 & & & & & & & 0.873 & & & & & 0.224 & \\
\hline Normal & 154 & 100 & 0 & 0.0 & 0 & 0.0 & 0 & 0.0 & & 47 & 74.6 & 51 & 82.3 & 44 & 69.8 & & 11 & 78.6 & 13 & 76.4 & 130 & 75.6 & & 33 & 76.8 & 120 & 76.9 & \\
\hline Deletion & 0 & 0.0 & 11 & 100 & 0 & 0.0 & 0 & 0.0 & & 3 & 4.8 & 3 & 4.8 & 3 & 4.8 & & 0 & 0.0 & 2 & 11.8 & 9 & 5.2 & & 0 & 0.0 & 11 & 7.0 & \\
\hline Amplification & 0 & 0.0 & 0 & 0.0 & 18 & 100 & 0 & 0.0 & & 4 & 6.3 & 2 & 3.2 & 11 & 17.5 & & 1 & 7.1 & 1 & 5.9 & 16 & 9.3 & & 5 & 11.6 & 12 & 7.8 & \\
\hline Polysomy & 0 & 0.0 & 0 & 0.0 & 0 & 0.0 & 20 & 100 & & 9 & 14.3 & 6 & 9.7 & 5 & 7.9 & & 2 & 14.3 & 1 & 5.9 & 17 & 9.9 & & 5 & 11.6 & 13 & 8.3 & \\
\hline EGFR Protein level & & & & & & & & 0.164 & & & & & & & & - & & & & & & 0.180 & & & & & 0.110 & \\
\hline Lower tercile & 47 & 33.1 & 3 & 33.3 & 4 & 23.5 & 9 & 45.0 & & 64 & 100 & 0 & 0.0 & 0 & 0.0 & & 3 & 27.3 & 4 & 26.7 & 57 & 35.0 & & 9 & 21.4 & 53 & 36.8 & \\
\hline Middle tercile & 51 & 35.9 & 3 & 33.3 & 2 & 11.8 & 6 & 30.0 & & 0 & 0.0 & 62 & 100 & 0 & 0.0 & & 7 & 63.6 & 4 & 26.7 & 51 & 31.3 & & 14 & 33.3 & 47 & 32.6 & \\
\hline Upper tercile & 44 & 31.0 & 3 & 33.3 & 11 & 64.7 & 5 & 25.0 & & 0 & 0.0 & 0 & 0.0 & 63 & 100 & & 1 & 9.1 & 7 & 46.6 & 55 & 33.7 & & 19 & 45.3 & 44 & 30.6 & \\
\hline PIK3CA Mutations & & & & & & & & 0.873 & & & & & & & 0.180 & & & & & & & & - & & & & 0.565 & \\
\hline Exon 9 & 11 & 7.1 & 0 & 0.0 & 1 & 5.6 & 2 & 10.0 & & 3 & 4.7 & 7 & 11.3 & 1 & 1.60 & & 14 & 100 & 0 & 0.0 & 0 & 0.0 & & 1 & 2.3 & 12 & 7.6 & \\
\hline Exon 20 & 13 & 8.4 & 2 & 18.2 & 1 & 5.6 & 1 & 5.0 & & 4 & 6.2 & 4 & 6.4 & 7 & 11.1 & & 0 & 0.0 & 17 & 100 & 0 & 0.0 & & 3 & 7.0 & 12 & 7.6 & \\
\hline No & 130 & 84.5 & 9 & 81.8 & 16 & 88.8 & 17 & 85.0 & & 57 & 89.1 & 51 & 82.3 & 55 & 87.3 & & 0 & 0.0 & 0 & 0.0 & 173 & 100 & & 39 & 90.7 & 133 & 84.8 & \\
\hline PTEN Status & & & & & & & & 0.224 & & & & & & & 0.110 & & & & & & & 0.565 & & & & & & - \\
\hline Deletion & 33 & 21.6 & 0 & 0.0 & 5 & 29.4 & 5 & 27.8 & & 9 & 14.5 & 14 & 23.0 & 19 & 30.2 & & 1 & 7.7 & 3 & 20.0 & 39 & 22.7 & & 43 & 100 & 0 & 0.0 & \\
\hline No deletion & 120 & 78.4 & 11 & 100 & 12 & 70.6 & 13 & 72.2 & & 53 & 85.5 & 47 & 77.0 & 44 & 69.8 & & 12 & 92.3 & 12 & 80.0 & 133 & 77.3 & & 0 & 0.0 & 157 & 100 & \\
\hline
\end{tabular}




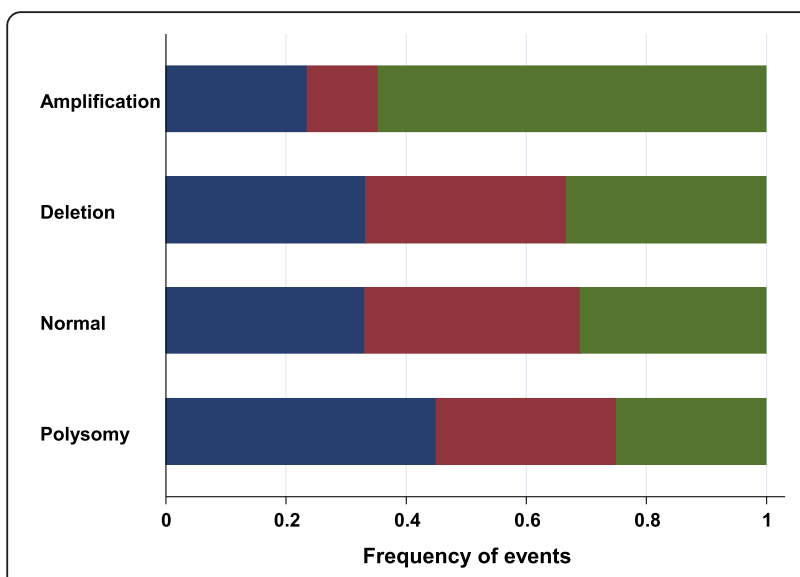

Fig. 1 Correlation between EGFR gene status and EGFR protein levels (blue, lower tercile; red, middle tercile; green, upper tercile)

(Table 4, Fig. 2). These parameters remained significant independent prognostic factors in the two subgroup analyses (in the population of tumors excluding the 11 cases with HR values between $1 \%$ and $9 \%$ [ $n=193]$, as well as in the ductal tumors population $[n=163])$.

\section{Discussion}

We performed an extensive analysis of the EGFR/ PI3K/PTEN axis alterations and of their clinicopathological and prognostic implications in a set of 204 European patients with TNBC. The results obtained in our series are in accordance with comprehensive evaluations of the mutational spectrum of TNBC reported in the literature [27]. We previously reported [7] the absence of EGFR-activating mutation in this series of TNBC. We showed a statistically significant association between EGFR gene amplification and EGFR protein expression. As we did not chose to classify our series of tumors as basal-like or nonbasal-like, but rather to evaluate quantitatively the level of EGFR protein expression, it appeared that a quantitative continuous test such as the one offered by the biochemical assay was the more relevant to achieve our objective, and thus selected this method for the EGFR protein evaluation. Our results are consistent with the study by Bhargava et al. [8] who found a correlation between EGFR gene amplification (detected in $6 \%$ of their breast cancer patients) and EGFR overexpression. Interestingly, $73 \%$ of tumors harboring EGFR gene amplification were TNBC (the total number of TNBC in this series was not reported). However, they could not differentiate between chromosome 7 polysomy and true EGFR gene amplification, as they used only one EGFR gene probe for CISH. Two recent reports $[11,28]$ also found a significant correlation between EGFR protein overexpression (evaluated by IHC) and EGFR gene amplification and chromosome 7 polysomy by dual probe (EGFR/CEP7) FISH analysis. However, as concomitant evaluation of the prognostic value of EGFR gene alterations and EGFR protein expression (by IHC and biochemically) has never been reported, it is currently impossible to say which is the best method(s) to assess EGFR status as a prognostic indicator in TNBC.

The PI3K pathway is up-regulated in basal-like cancers and in TNBC. The majority of the reported mutations is located within the helical (exon 9) and the kinase (exon 20) domains of the PI3K catalytic subunit p110 alpha and result in constitutive PI3K activation, AKT signaling induction and oncogenic transformation [29]. In our TNBC cohort, exon 9 PIK3CA activating mutations were detected in $6.7 \%$ and exon 20 mutations in $8.3 \%$ of tumor samples, in agreement with previously published reports on PIK3CA mutations in patients with TNBC [14, 30-32]. The frequency and clinical impact of PIK3CA mutations need to be assessed in homogeneous biological subgroups of breast cancers, as the prevalence and biological implications of these mutations appear to vary in the different subgroups [13, 14, 31]. Arsenic et al. reported an overall PIK3CA mutation frequency of $15.8 \%$ in breast cancer and of $13.2 \%$ in TNBC [30]. Moreover, mutations in exon 20 were more numerous compared with those in exon 9, in agreement with other works $[14,31]$ and our results. Although exon 9 and exon 20 PIK3CA mutations do not appear to be mutually exclusive and they could have a synergistic effect [33], they were never concomitantly detected in our cohort.

Then we showed that exon 9 PIK3CA mutations were independent prognostic factors in TNBC while exon 20 PIK3CA mutations did not. Previous studies analyzed PIK3CA mutation prognostic impact in the whole breast cancer population and not specifically in TNBC [34], or evaluated together exon 9 and exon 20 PIK3CA mutations [32, 35], or analyzed their prognostic impact in small series $(<100$ patients with TNBC) [30,35]. Interestingly, Zhao et al. [33] showed that PIK3CA mutations in exon 9 and exon 20 could be associated with different activation mechanisms. Specifically, the gain of function induced by exon 9 PIK3CA mutations is independent of binding to the PI3K regulatory subunit p85, but requires interaction with RAS-GTP. Conversely, exon 20 mutants do not require RAS-GTP binding, but are highly dependent on the interaction with p85. These molecular differences could, at least partially, explain the differential prognostic impact of exon 9 and 20 PIK3CA mutations in our series.

TNBC activation of downstream members of the PI3K signaling pathway is very common as indicated by the frequency of PTEN LOE, INPP4B loss and MAGI3 and $A K T 3$ activating translocations [36]. As we wanted to 
Table 3 Univariate analysis

\begin{tabular}{|c|c|c|c|c|c|c|c|}
\hline & \multirow[t]{2}{*}{$\mathrm{N}$} & \multicolumn{3}{|l|}{ RFS } & \multicolumn{3}{|l|}{ OS } \\
\hline & & Events & 5-y RFS & HR $(95 \%$ Cl) & Events & $5-y$ OS & HR $(95 \%$ Cl) \\
\hline \multicolumn{8}{|l|}{ Age } \\
\hline$<55$ years & 98 & 21 & 79.9 & 1 & 17 & 84.1 & 1 \\
\hline \multirow[t]{2}{*}{$\geq 55$ years } & 106 & 31 & 72.6 & $1.29[0.74 ; 2.24]$ & 30 & 78.9 & $1.51[0.83 ; 2.73]$ \\
\hline & & \multicolumn{3}{|c|}{$p=0.370$} & \multicolumn{3}{|c|}{$p=0.174$} \\
\hline \multicolumn{8}{|l|}{$\mathrm{T}$} \\
\hline $\mathrm{T} 1$ & 84 & 11 & 88.3 & 1 & 11 & 90.7 & 1 \\
\hline \multirow[t]{2}{*}{$\mathrm{T} 2+$} & 120 & 41 & 67.5 & $2.91[1.50 ; 5.67]$ & 36 & 74.7 & $2.48[1.26 ; 4.88]$ \\
\hline & & \multicolumn{3}{|c|}{$p=0.001$} & \multicolumn{3}{|c|}{$p=0.006$} \\
\hline \multicolumn{8}{|l|}{ N } \\
\hline N- & 132 & 20 & 86.9 & 1 & 21 & 89.0 & 1 \\
\hline \multirow[t]{2}{*}{$\mathrm{N}+$} & 72 & 32 & 56.1 & $3.56[2.03 ; 6.22]$ & 26 & 66.8 & $2.58[1.45 ; 4.59]$ \\
\hline & & \multicolumn{3}{|c|}{$p<0.001$} & \multicolumn{3}{|c|}{$p=0.001$} \\
\hline \multicolumn{8}{|l|}{ SBR-EE grade } \\
\hline $1-2$ & 69 & 17 & 79.9 & 1 & 15 & 86.3 & 1 \\
\hline \multirow[t]{2}{*}{3} & 132 & 35 & 73.7 & $1.13[0.63 ; 2.02]$ & 32 & 78.4 & $1.21[0.65 ; 2.24]$ \\
\hline & & \multicolumn{3}{|c|}{$p=0.676$} & \multicolumn{3}{|c|}{$p=0.541$} \\
\hline \multicolumn{8}{|l|}{ Histology } \\
\hline Ductal & 163 & 42 & 75.4 & 1 & 40 & 80.0 & 1 \\
\hline \multirow[t]{2}{*}{ Lobular/Other } & 41 & 10 & 78.7 & $0.93[0.47 ; 1.86]$ & 7 & 86.6 & $0.67[0.30 ; 1.49]$ \\
\hline & & \multicolumn{3}{|c|}{$p=0.848$} & \multicolumn{3}{|c|}{$p=0.325$} \\
\hline \multicolumn{8}{|l|}{ Adjuvant CT } \\
\hline No & 60 & 21 & 66.7 & 1 & 24 & 69.1 & 1 \\
\hline Yes & 142 & 31 & 80.1 & $0.60[0.35 ; 1.05]$ & 23 & 86.8 & $0.40[0.23 ; 0.71]$ \\
\hline & & $p=0.07$ & & & $p=0.00$ & & \\
\hline EGFR status & & & & & & & \\
\hline Normal/Deletion & 165 & 41 & 78.0 & 1 & 35 & 81.8 & 1 \\
\hline Ampl./Polysomy & 38 & 11 & 65.9 & $1.36[0.69 ; 2.65]$ & 12 & 78.5 & $1.80[0.93 ; 3.49]$ \\
\hline & & $p=0.36$ & & & $p=0.07$ & & \\
\hline PIK3CA status & & & & & & & \\
\hline No mutation & 173 & 40 & 78.0 & 1 & 36 & 83.2 & 1 \\
\hline Exon 9 & 14 & 7 & 61.5 & $2.62[1.17 ; 5.86]$ & 7 & 69.2 & $2.55[1.13 ; 5.74]$ \\
\hline Exon 20 & 17 & 5 & 67.8 & $1.38[0.54 ; 3.50]$ & 4 & 70.5 & $1.23[0.44 ; 3.46]$ \\
\hline & & $p=0.04$ & & & $p=0.06$ & & \\
\hline EGFR protein level & & & & & & & \\
\hline Lower and middle tercile & 126 & 30 & 79.4 & 1 & 27 & 84.1 & 1 \\
\hline Upper tercile & 63 & 20 & 66.0 & $1.54[0.87 ; 2.72]$ & 17 & 73.8 & $1.42[0.78 ; 2.62]$ \\
\hline & & $p=0.13$ & & & $p=0.24$ & & \\
\hline PTEN status & & & & & & & \\
\hline No deletion & 157 & 38 & 78.5 & 1 & 33 & 83.4 & 1 \\
\hline Deletion & 43 & 13 & 67.7 & $1.38[0.74 ; 2.60]$ & 13 & 75.1 & $1.66[0.87 ; 3.16]$ \\
\hline & & $p=0.30$ & & & $p=0.11$ & & \\
\hline
\end{tabular}


Table 4 Multivariate analysis (RFS)

\begin{tabular}{|c|c|c|c|}
\hline & $\mathrm{HR}$ & $95 \% \mathrm{Cl}$ & $p$ \\
\hline T & & & 0.008 \\
\hline $\mathrm{T} 1$ & 1 & & \\
\hline $\mathrm{T} 2+$ & 2.48 & {$[1.21 ; 5.07]$} & \\
\hline N & & & $<0.001$ \\
\hline $\mathrm{N}-$ & 1 & & \\
\hline $\mathrm{N}+$ & 4.17 & {$[2.23 ; 7.78]$} & \\
\hline Adjuvant CT & & & 0.003 \\
\hline No & 1 & & \\
\hline Yes & 0.39 & {$[0.22 ; 0.70]$} & \\
\hline PIK3CA Exon 9 Mutation & & & 0.001 \\
\hline No & 1 & & \\
\hline Yes & 6.38 & {$[2.42 ; 16.8]$} & \\
\hline EGFR protein level & & & 0.011 \\
\hline Lower and middle tercile & 1 & & \\
\hline Upper tercile & 2.22 & {$[1.22 ; 4.03]$} & \\
\hline
\end{tabular}

evaluate the most stable PTEN modifications, we considered that genomic alterations were the most relevant way to identify stable PTEN loss of function. Thus, the evaluation of PTEN deletions using the MLPA methods appeared the most robust way to identify a true PTEN deficiency in our population. PTEN deletions were detected in $21.50 \%$ and were significantly associated with grade III tumors $(p<0.001)$. PIK3CA mutations and PTEN loss are considered to be nearly mutually exclusive in breast tumors [11, 14], a characteristic shared by our series, as only four tumors presented concomitantly a PTEN deletion and a PIK3CA activating mutation (one in exon 9, three in exon 20, Table 2). PTEN dysregulation, observed in 16.6 to $63 \%$ of TNBC depending on the evaluation method and the disease stage [17, 35, 37, 38], has been consistently reported to be associated with poor prognosis in these patients [37, 38]. The lack of significant association between PTEN deletion and RFS/OS in our study could be linked to the fact that we evaluated exclusively PTEN deletions, rather than PTEN LOE, and the frequency of PTEN abnormalities (20.1\%) was thus lower than in classical LOE studies [17, 35, 37, 38]. An extensive evaluation of the different mechanisms responsible for PTEN LOE, together with PTEN expression by IHC, could be useful for understanding its clinical and biological implications in our population.

A potential pitfall of our study could be linked to the choice of a European definition of TNBC, considering a $<10 \%$ negativity threshold for the determination of the hormone receptor status. However, the fact that the exclusion of the 11 cases with HR values between 1 and $9 \%$ did not change the multivariate analysis results, and the fact that recent biological studies showed a close biologic similarity between the $<1 \%$ HR and 1-9 \% HR population [39], both strengthen our results.

\section{Conclusions}

High EGFR protein expression and exon 9 PIK3CA activating mutations are independent prognostic factors in TNBC. These different molecular abnormalities could affect TNBC sensitivity to various anticancer treatments under development, such as mTOR inhibitors, PARP inhibitors or androgen receptor inhibitors. Therefore, it is now important to globally evaluate the EGFR/PI3K/PTEN pathway, together with androgen receptor and DNA repair deficiency status, to better identify different TNBC subgroups that could be sensitive to various kinase inhibitors, including anti-PI3K targeted therapies, or specific targeted therapy combinations.

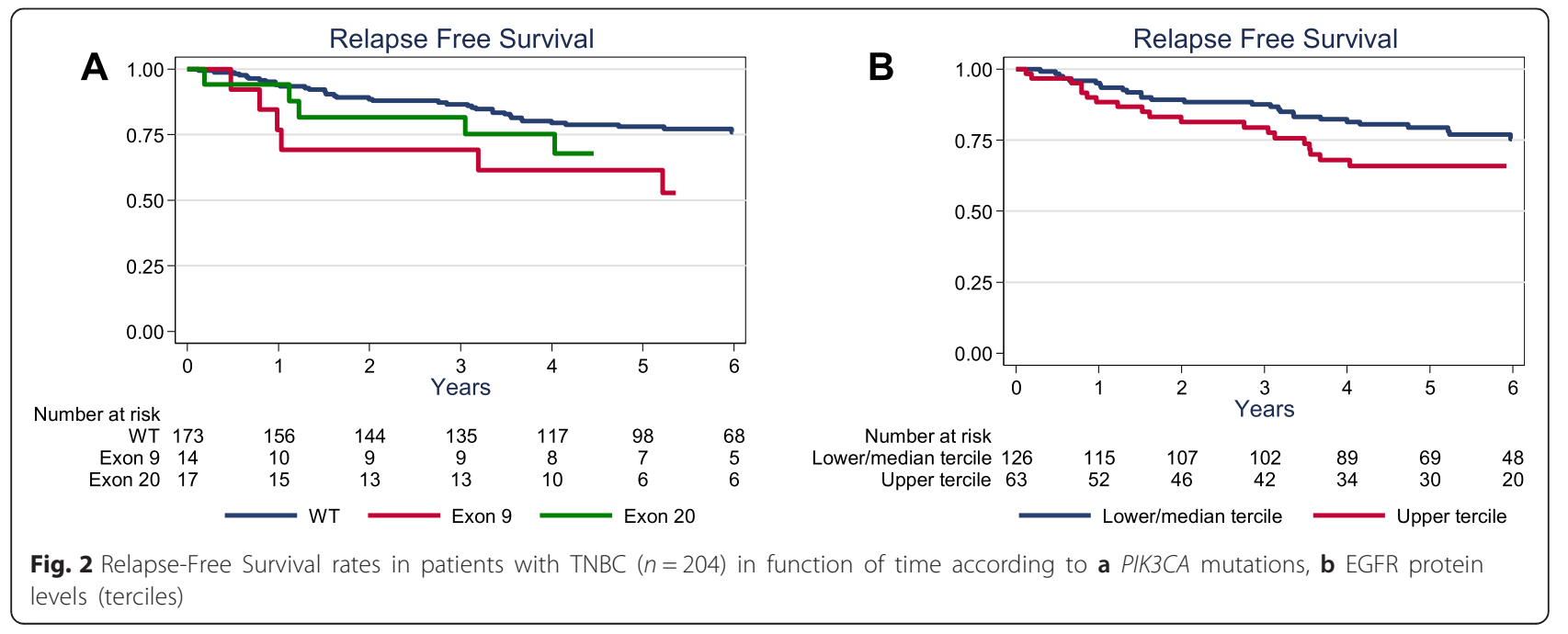




\section{Additional files}

Additional file 1: Table S1. Primers for PIK3CA exon 9 and 20 mutation analysis. (DOCX $17 \mathrm{~kb}$ )

Additional file 2: Table S2. Mix of probes in the Salsa MPLA kit for the detection of PTEN and Chr10 genomic abnormalities EX: exon; LPO: 5 half of the probe, RPO: $3^{\prime}$ half of the probe. (DOCX $44 \mathrm{~kb}$ )

Additional file 3: Table S3. Exon 9 and 20 PIK3CA mutations in triple negative breast cancer specimens. (DOCX $20 \mathrm{~kb}$ )

Additional file 4: Relapse Free and Overall Survival. (PPTX 55 kb)

Additional file 5: Relapse Rates of the patients with TNBC according to time $(\boldsymbol{n}=\mathbf{2 0 4})$. (PPTX $103 \mathrm{~kb})$

\section{Competing interests}

The authors declare that they have no competing interests.

\section{Authors' contributions}

Conception and design: WJ, P-MM, GR, P-JL. Development of methodology: FF, WJ, EL-C, CM, P-JL. Acquisition of data, acquired and managed patients, provided facilities, etc.: WJ, EL-C, P-EC, FB, GR, P-JL. Analysis and interpretation of data (e.g., statistical analysis, biostatistics, computational analysis): WJ, CM, P-JL. Writing, review, and/or revision of the manuscript: WJ, CM, FF, EL-C, PMM, P-EC, FB, GR, P-JL. Administrative, technical, or material support (i.e., reporting or organizing data, constructing databases): EL-C, CM, P-JL. Study supervision: WJ, P-JL. All authors have read and approved the manuscript.

\section{Acknowledgments}

We are grateful to Sylvie Roques, Romain Senal and Cathy Viglianti for technical assistance and biobanking management.

\section{Funding}

This work was supported by the Montpellier Cancer Institute Val d'Aurelle. The Department of Biology and Oncogenetics is a "génétique moléculaire des cancers" facility and is supported by grants from the French National Institute of Cancer (INCa).

\section{Author details}

'Department of Medical Oncology, Montpellier Cancer Institute Val d'Aurelle, 208, rue des Apothicaires, Montpellier F-34298, France. ${ }^{2}$ Translationnal Research Unit, Montpellier Cancer Institute Val d'Aurelle, 208, rue des Apothicaires, Montpellier F-34298, France. ${ }^{3}$ Biostatistical Research Unit, Montpellier Cancer Institute Val d'Aurelle, 208, rue des Apothicaires, Montpellier F-34298, France. ${ }^{4}$ Department of Oncobiology, Assistance Publique - Hôpitaux de Marseille, Boulevard Pierre Dramard, Marseille F-13916, France. ${ }^{5}$ Department of Surgical Oncology, Montpellier Cancer Institute Val d'Aurelle, 208, rue des Apothicaires, Montpellier F-34298, France. ${ }^{6}$ Department of Pathology, Montpellier Cancer Institute Val d'Aurelle, 208, rue des Apothicaires, Montpellier F-34298, France. ${ }^{7}$ Department of Oncogenetics, Montpellier Cancer Institute Val d'Aurelle, 208, rue des Apothicaires, Montpellier F-34298, France. ${ }^{8}$ Biological Ressources Center, Montpellier Cancer Institute Val d'Aurelle, 208, rue des Apothicaires, F-34298 Montpellier, France.

Received: 3 July 2015 Accepted: 5 December 2015

Published online: 18 December 2015

\section{References}

1. Dent R, Trudeau M, Pritchard Kl, Hanna WM, Kahn HK, Sawka CA, et al. Triple-negative breast cancer: clinical features and patterns of recurrence. Clin Cancer Res. 2007;13(15 Pt 1):4429-34.

2. Rakha EA, El-Sayed ME, Green AR, Lee AH, Robertson JF, Ellis IO. Prognostic markers in triple-negative breast cancer. Cancer. 2007;109(1):25-32.

3. Viale G, Rotmensz N, Maisonneuve P, Bottiglieri L, Montagna E, Luini A, et al. Invasive ductal carcinoma of the breast with the "triple-negative" phenotype: prognostic implications of EGFR immunoreactivity. Breast Cancer Res Treat. 2009;116(2):317-28.

4. Burness ML, Grushko TA, Olopade Ol. Epidermal growth factor receptor in triple-negative and basal-like breast cancer: promising clinical target or only a marker? Cancer J. 2010;16(1):23-32.
5. Klijn JG, Berns PM, Schmitz PI, Foekens JA. The clinical significance of epidermal growth factor receptor (EGF-R) in human breast cancer: a review on 5232 patients. Endocr Rev. 1992;13(1):3-17.

6. Milanezi F, Carvalho S, Schmitt FC. EGFR/HER2 in breast cancer: a biological approach for molecular diagnosis and therapy. Expert Rev Mol Diagn. 2008:8(4):417-34.

7. Jacot W, Lopez-Crapez E, Thezenas S, Senal R, Fina F, Bibeau F, et al. Lack of EGFR-activating mutations in European patients with triple-negative breast cancer could emphasise geographic and ethnic variations in breast cancer mutation profiles. Breast Cancer Res. 2011;13(6):R133.

8. Bhargava R, Gerald WL, Li AR, Pan Q, Lal P, Ladanyi M, et al. EGFR gene amplification in breast cancer: correlation with epidermal growth factor receptor mRNA and protein expression and HER-2 status and absence of EGFR-activating mutations. Mod Pathol. 2005;18(8):1027-33.

9. Toyama T, Yamashita H, Kondo N, Okuda K, Takahashi S, Sasaki H, et al. Frequently increased epidermal growth factor receptor (EGFR) copy numbers and decreased BRCA1 mRNA expression in Japanese triple-negative breast cancers. BMC Cancer. 2008;8:309.

10. Nakajima H, Ishikawa $Y$, Furuya M, Sano T, Ohno Y, Horiguchi J, et al. Protein expression, gene amplification, and mutational analysis of EGFR in triplenegative breast cancer. Breast Cancer. 2012.

11. Martin V, Botta F, Zanellato E, Molinari F, Crippa S, Mazzucchelli L, et al. Molecular characterization of EGFR and EGFR-downstream pathways in triple negative breast carcinomas with basal like features. Histol Histopathol. 2012;27(6):785-92.

12. Gumuskaya B, Alper M, Hucumenoglu S, Altundag K, Uner A, Guler G. EGFR expression and gene copy number in triple-negative breast carcinoma. Cancer Genet Cytogenet. 2010;203(2):222-9.

13. Miller TW, Rexer BN, Garrett JT, Arteaga CL. Mutations in the phosphatidylinositol 3-kinase pathway: role in tumor progression and therapeutic implications in breast cancer. Breast Cancer Res. 2011;13(6):224.

14. Saal LH, Holm K, Maurer M, Memeo L, Su T, Wang X, et al. PIK3CA mutations correlate with hormone receptors, node metastasis, and ERBB2, and are mutually exclusive with PTEN loss in human breast carcinoma. Cancer Res. 2005;65(7):2554-9.

15. Lopez-Knowles E, O'Toole SA, McNeil CM, Millar EK, Qiu MR, Crea P, et al. PI3K pathway activation in breast cancer is associated with the basal-like phenotype and cancer-specific mortality. Int J Cancer. 2010;126(5):1121-31.

16. Kalinsky K, Jacks LM, Heguy A, Patil S, Drobnjak M, Bhanot UK, et al. PIK3CA mutation associates with improved outcome in breast cancer. Clin Cancer Res. 2009;15(16):5049-59.

17. Gonzalez-Angulo AM, Ferrer-Lozano J, Stemke-Hale K, Sahin A, Liu S, Barrera JA, et al. PI3K pathway mutations and PTEN levels in primary and metastatic breast cancer. Mol Cancer Ther. 2011;10(6):1093-101.

18. Gonzalez-Angulo AM, Stemke-Hale K, Palla SL, Carey M, Agarwal R, Meric-Berstam F, et al. Androgen receptor levels and association with PIK3CA mutations and prognosis in breast cancer. Clin Cancer Res. 2009;15(7):2472-8

19. Lamy PJ, Fina F, Bascoul-Mollevi C, Laberenne AC, Martin PM, Ouafik L, et al. Quantification and clinical relevance of gene amplification at chromosome 17q12-q21 in human epidermal growth factor receptor 2-amplified breast cancers. Breast Cancer Res. 2011;13(1):R15.

20. Lamy PJ, Nanni I, Fina F, Bibeau F, Romain S, Dussert C, et al. Reliability and discriminant validity of HER2 gene quantification and chromosome 17 aneusomy analysis by real-time PCR in primary breast cancer. Int J Biol Markers. 2006;21(1):20-9.

21. Goldhirsch A, Glick JH, Gelber RD, Coates AS, Thurlimann B, Senn HJ. Meeting highlights: international expert consensus on the primary therapy of early breast cancer 2005. Ann Oncol. 2005;16(10):1569-83.

22. Jacot W, Gutowski M, Azria D, Romieu G. Adjuvant early breast cancer systemic therapies according to daily used technologies. Crit Rev Oncol Hematol. 2011.

23. Lamy PJ, Verjat T, Servanton AC, Paye M, Leissner P, Mougin B. Urokinasetype plasminogen activator and plasminogen activator inhibitor type-1 mRNA assessment in breast cancer by means of NASBA: correlation with protein expression. Am J Clin Pathol. 2007;128(3):404-13.

24. Schmidt M, Victor A, Bratzel D, Boehm D, Cotarelo C, Lebrecht A, et al. Long-term outcome prediction by clinicopathological risk classification algorithms in node-negative breast cancer-comparison between Adjuvant! St Gallen, and a novel risk algorithm used in the prospective randomized Node-Negative-Breast Cancer-3 (NNBC-3) trial. Ann Oncol. 2009;20(2):258-64. 
25. Secq V, Villeret J, Fina F, Carmassi M, Carcopino X, Garcia S, et al. Triple negative breast carcinoma EGFR amplification is not associated with EGFR, Kras or ALK mutations. Br J Cancer. 2014;110(4):1045-52.

26. Cho EY, Chang MH, Choi YL, Lee JE, Nam SJ, Yang JH, et al. Potential candidate biomarkers for heterogeneity in triple-negative breast cancer (TNBC). Cancer Chemother Pharmacol. 2011;68(3):753-61.

27. Shah SP, Roth A, Goya R, Oloumi A, Ha G, Zhao Y, et al. The clonal and mutational evolution spectrum of primary triple-negative breast cancers. Nature. 2012;486(7403):395-9.

28. Park HS, Jang MH, Kim EJ, Kim HJ, Lee HJ, Kim YJ, et al. High EGFR gene copy number predicts poor outcome in triple-negative breast cancer. Mod Pathol. 2014;27(9):1212-22.

29. Samuels Y, Wang Z, Bardelli A, Silliman N, Ptak J, Szabo S, et al. High frequency of mutations of the PIK3CA gene in human cancers. Science. 2004;304(5670):554.

30. Arsenic R, Lehmann A, Budczies J, Koch I, Prinzler J, Kleine-Tebbe A, et al. Analysis of PIK3CA mutations in breast cancer subtypes. Appl Immunohistochem Mol Morphol. 2014;22(1):50-6.

31. Stemke-Hale K, Gonzalez-Angulo AM, Lluch A, Neve RM, Kuo WL, Davies M, et al. An integrative genomic and proteomic analysis of PIK3CA, PTEN, and AKT mutations in breast cancer. Cancer Res. 2008;68(15):6084-91.

32. Cizkova M, Susini A, Vacher S, Cizeron-Clairac G, Andrieu C, Driouch $\mathrm{K}$, et al. PIK3CA mutation impact on survival in breast cancer patients and in ERalpha, PR and ERBB2-based subgroups. Breast Cancer Res. 2012;14(1):R28.

33. Zhao L, Vogt PK. Helical domain and kinase domain mutations in p110alpha of phosphatidylinositol 3-kinase induce gain of function by different mechanisms. Proc Natl Acad Sci U S A. 2008;105(7):2652-7.

34. Liu YR, Jiang YZ, Zuo WJ, Yu KD, Shao ZM. PIK3CA mutations define favorable prognostic biomarkers in operable breast cancer: a systematic review and meta-analysis. OncoTargets and therapy. 2014;7:543-52.

35. Hashimoto K, Tsuda H, Koizumi F, Shimizu C, Yonemori K, Ando M, et al. Activated PI3K/AKT and MAPK pathways are potential good prognostic markers in node-positive, triple-negative breast cancer. Ann Oncol. 2014 25(10):1973-9

36. Banerji S, Cibulskis K, Rangel-Escareno C, Brown KK, Carter SL, Frederick AM, et al. Sequence analysis of mutations and translocations across breast cancer subtypes. Nature. 2012:486(7403):405-9.

37. Inanc M, Ozkan M, Karaca H, Berk V, Bozkurt O, Duran AO, et al. Cytokeratin 5/6, C-Met expressions, and PTEN loss prognostic indicators in triple-negative breast cancer. Med Oncol. 2014;31(1):801.

38. Iqbal J, Thike AA, Cheok PY, Tse GM, Tan PH. Insulin growth factor receptor-1 expression and loss of PTEN protein predict early recurrence in triple-negative breast cancer. Histopathology. 2012;61 (4):652-9.

39. Sanford RA, Song J, Gutierrez-Barrera AM, Profato J, Woodson A, Litton JK et al. High incidence of germline BRCA mutation in patients with ER low-positive/PR low-positive/HER-2 neu negative tumors. Cancer. 2015;121(19):3422-7.

\section{Submit your next manuscript to BioMed Central and we will help you at every step:}

- We accept pre-submission inquiries

- Our selector tool helps you to find the most relevant journal

- We provide round the clock customer support

- Convenient online submission

- Thorough peer review

- Inclusion in PubMed and all major indexing services

- Maximum visibility for your research

Submit your manuscript at wuw biomedcentral.com/submit

CBiomed Central 